inhibition and H-reflex threshold in amyotrophic lateral sclerosis (ALS) patients. Neurology 1985;35 (Suppl 1): 106

13 Guiloff RJ, Stålberg E, Eckland DJA, et al. Electrophysiological observations in patients with motor neuron disease receiving a TRH analogue (RX77368). J Neurol Neurosurg Psychiatry 1987;50:1633-40.

14 Stålberg E. Macro EMG, a new recording technique. $J$ Neurol Neurosurg Psychiatry 1980;43:475-82.
15 Stålberg E, Fawcett PRW. Macro EMG in healthy subjects of different ages. $J$ Neurol Neurosurg Psychiatry 1982;45:870-8.

16 Stålberg E, Trontelji J. Single Fibre Electromyography, Surrey. The Mirvalle Press Ltd, UK 1979.

17 Modarres-Sadeghi H, Guiloff RJ. Subacute administration of a TRH analogue (RX77368) in motor neuron disease: an open study. $J$ Neurol Neurosurg Psychiatry (in press).

\section{The thalamic syndrome of Dejerine and Roussy}

In a series of publications between 1903 and 1907, Dejerine and Roussy provided the earliest formal accounts of "Le syndrome thalamique". The better known of these names conjures up a legacy of classic eponymous syndromes: facioscapulo-humeral dystrophy (Landouzy-Dejerine); hypertrophic interstitial polyneuritis (Dejerine-Sottas); olivo-ponto-cerebellar atrophy (Dejerine \& Andre-Thomas). Dejerine also described: alexia without agraphia (pure alexia) and alexia with agraphia.

The precipitation of root pain by sneezing and coughing should also be referred to as Dejerine's sign; he popularised it in a 1905 paper and in his later text Traité des maladies de la moelle épinière, 1909.

Jules Dejerine was born in Geneva in 1849 , graduated in medicine in Paris in 1879 and followed Raymond in the chair held by Charcot at Salpêtrière. He married Augusta Klumpke who in 1885 left for posterity Contributions a l'étude des paralysies radiculaires du plexus brachial. He was elected to the Academy of Medicine in 1908 and died on February 26th 1917.

The 1906 paper $^{1}$ in translation" described "a syndrome characterised by:

"1. A slight hemiplegia, usually without contracture and rapidly regressive.

2. A persistent superficial hemianaesthesia of an organic character, which can in some cases be replaced by cutaneous hyperaesthesia but is always accompanied by marked and persistent disturbances of deep sensation.

3. Mild hemiataxia and more or less complete astereognosis.

4. Severe, persistent, paroxysmal and often intolerable pains on the hemiplegic side, not yielding to any analgesic treatment.

5. Choreoathetoid movements in the limbs on the paralyzed side."

This definition was followed by a "Clinical Study" elaborating the salient features, emphasising the mildness of the hemiplegia, its improvement, but noting "the sensory phenomena usually persist until death. The symptoms of the thalamic syndrome appear a few months or even better a year after the hemiplegia... the chorea is not a major hemichorea ... but small movements... in the fingers and hand.' The hemiataxia "is slight, apparently not connected with the intensity of sensory disturbances... an uneasiness, a certain hesitation... Reflexes sometimes slightly exaggerated; sometimes almost normal. The cutaneous reflexes and the plantar reflex are normal or absent. The absence of the
Babinski response in all our cases, despite the pyramidal degeneration ... deserves mention."

"Sensory disorders... dominate the symptomatology. (a) Objective sensation - superficial, involving touch, pain and temperature, never absolute, predominates distally, and on the trunk and face goes slightly over the midline 1 to $2 \mathrm{~cm}$. Deep sensation is affected much more ... osseous sensitivity, complete loss of muscle sense, ... sensation of weight ... position sense ... "stereognosis" is always affected." (b) Subjective sensation-pain on the hemiplegic side "of central origin", dating from the onset or a few months later ... pains continuous, with paroxysmal exacerbations, bringing cries from the patient, keeping them from sleep ... provoked by touching, pinprick, contact with cold and heat and pressure... not suppressed by analgesic treatment... suffering is sometimes intolerable."

The pathological anatomy was based on three specimens. They concluded "when the lesion occupies the external $\_$일 nucleus (external and posterior part) extending through the $\bar{\sigma}$ internal and median nuclei of the thalamus, involving only a part of the fibres of the posterior limb of the internal capsule, the clinical picture of the thalamic syndrome results."

It was in 1923 that Foix and Masson showed the most common cause was "Le syndrome de l'artère cérébrale posterieure". ${ }^{3}$

\section{References}

JMS PEARCE

1 Dejerine J, Roussy G. Le syndrome thalamique. Rev Neurol (Paris) 1906;14:521-32.

2 Wilkins RH, Brody IA. The thalamic syndrome. Arch Neurol 1969;20:559-62.

3 Foix C, Masson A. Le syndrome de l'artère cérébrale posterieure. Presse Med 1923;31:361-65.

\section{Huntington's chorea}

"It is as common and is indeed, I believe, more common among men than women, while I am not aware that season or complexion has any influence in the matter. There are three marked peculiarities in this disease: (1) Its hereditary nature. (2) A tendency to insanity and suicide. (3) Its manifesting itself as a grave disease only in adult life".

Huntington George. On Chorea, The Medical and Surgical Reporter $1872 ; 26: 317-321$

RT ROSS 